\title{
Decline of placental malaria in southern Ghana after the implementation of intermittent preventive treatment in pregnancy Lena Hommerich ${ }^{1}$, Christa von Oertzen ${ }^{2}$, George Bedu-Addo ${ }^{3}$, Ville Holmberg ${ }^{1,4}$, Patrick A Acquah ${ }^{2}$, Teunis A Eggelte ${ }^{5}$, Ulrich Bienzle ${ }^{1}$ and Frank P Mockenhaupt*1
}

Address: ${ }^{1}$ Institute of Tropical Medicine and International Health, Charité - University Medicine, Berlin, Germany, ${ }^{2}$ Presbyterian Mission Hospital, Agogo, Ghana, ${ }^{3}$ Dept. of Medicine, Komfo Anoyke Teaching Hospital, School of Medical Sciences, Kwame Nkrumah University of Science and Technology, Ghana, ${ }^{4}$ Department of Bacteriology and Immunology, Haartman Institute, University of Helsinki, Helsinki, Finland and ${ }^{5}$ Division of Infectious Diseases, Tropical Medicine and AIDS, Academic Medical Centre, Amsterdam, The Netherlands

Email: Lena Hommerich - l.hommerich@web.de; Christa von Oertzen - c.v.oertzen@gmx.de; George Bedu-Addo - gbeduaddo@gmail.com; Ville Holmberg - ville.holmberg@helsinki.fi; Patrick A Acquah - padjeiacquah@yahoo.co.uk; Teunis A Eggelte - t.a.eggelte@amc.uva.nl; Ulrich Bienzle - ulrich.bienzle@charite.de; Frank P Mockenhaupt* - frank.mockenhaupt@charite.de

* Corresponding author

Published: 8 November 2007

Malaria Journal 2007, 6: I44 doi:I0.1 I86/1475-2875-6-144
Received: 13 August 2007

Accepted: 8 November 2007

This article is available from: http://www.malariajournal.com/content/6/1/144

(c) 2007 Hommerich et al; licensee BioMed Central Ltd.

This is an Open Access article distributed under the terms of the Creative Commons Attribution License (http://creativecommons.org/licenses/by/2.0), which permits unrestricted use, distribution, and reproduction in any medium, provided the original work is properly cited.

\begin{abstract}
Background: Intermittent preventive treatment in pregnancy with sulphadoxine-pyrimethamine (IPTp-SP) has been adopted as policy by many countries in sub-Saharan Africa. However, data on the post-implementation effectiveness of this measure are scarce.
\end{abstract}

Methods: Clinical and parasitological parameters were assessed among women delivering at a district hospital in rural southern Ghana in the year 2000 when pyrimethamine chemoprophylaxis was recommended $(n=839)$ and in $2006(n=226)$, approximately one year after the implementation of IPTP-SP. Examinations were performed in an identical manner in 2000 and 2006 including the detection of placental Plasmodium falciparum infection by microscopy, histidine-rich protein 2, and PCR.

Results: In 2006, $77 \%$ of the women reported to have taken IPTP-SP at least once (26\%, twice; $24 \%$, thrice). In 2006 as compared to 2000 , placental $P$. falciparum infection was reduced by $43-57 \%$ $(P<0.000 \mathrm{I})$ and maternal anaemia by $33 \%(P=0.0009)$, and median birth weight was I $30 \mathrm{~g}$ higher $(P=0.02)$. In 2006, likewise, women who had taken $\geq$ I dose of IPTP-SP revealed less infection and anaemia and their children tended to have higher birth weights as compared to women who had not used IPTP-SP. However, placental P. falciparum infection was still observed in I I\% (microscopy) to $26 \%$ (PCR) of those women who had taken three doses of IPTP-SP.

Conclusion: In southern Ghana, placental malaria and maternal anaemia have declined substantially and birth weight has increased after the implementation of IPTP-SP. Likely, these effects can further be increased by improving IPTP-SP coverage and adherence. However, the remnant prevalence of infection in women having taken three doses of IPTP-SP suggests that additional antimalarial measures are needed to prevent malaria in pregnancy in this region. 


\section{Background}

Malaria in pregnancy is a major cause of maternal, foetal and infant morbidity and mortality in sub-Saharan Africa. Although frequently asymptomatic, consequences of Plasmodium falciparum infection in pregnancy comprise maternal anaemia, abortion, stillbirth, intrauterine growth retardation, low birth weight (LBW), preterm delivery, and up to 200,000 attributable infant deaths per year [1-5]. Primiparae are particularly vulnerable as immune mechanisms preventing placental sequestration of pregnancy-specific parasite strains are weak or absent $[6,7]$.

Intermittent preventive treatment in pregnancy (IPTp) denotes the administration of a curative dose of an antimalarial, commonly sulphadoxine-pyrimethamine (SP), during routine antenatal care, irrespective of parasitaemia being present or not. Given twice or thrice in the second and third trimester of pregnancy, IPTp-SP has been shown to be safe and to reduce placental malaria, maternal anaemia, and LBW [8-13]. IPTp with $\geq 2$ doses of SP is currently recommended by the World Health Organisation [14], and has become policy in much of sub-Saharan Africa. Nevertheless, coverage with IPTp still needs to be substantially improved $[15,16]$ and the effectiveness of IPTp may be endangered by spreading and intensifying SP resistance $[17,18]$. Although most clinical trials on IPTp-SP were conducted in East Africa [8-10,19] the strategy was rapidly adopted also in West Africa where its effectiveness is less well documented [20]. Consequently, there is an urgent need to monitor the post-implementation effectiveness of IPTp in this region.

In southern Ghana, malaria in pregnancy and related morbidity are frequent [21-23]. Ghana started the implementation of IPTp with three recommended doses of SP at the end of 2004. In this country, SP achieves cure rates within 28 days of follow-up of $14 \%$ and $11 \%$ in children and pregnant women with uncomplicated malaria, respectively [24,25]. Here, parasitological and clinical parameters were compared among women delivering at the Presbyterian Mission Hospital in Agogo, southern Ghana, before (2000) and after (2006) the implementation of IPTp. In addition, these parameters were examined with respect to the usage of IPTp among women delivering in 2006 and the number of doses taken.

\section{Methods}

Agogo is a community of some 30,000 inhabitants; subsistence farming, trade and mining are the main income sources in that region, and malaria is hyper- to holoenedemic [26]. The characteristics of 839 women with live singleton delivery recruited in 2000 have been described in detail elsewhere [23]. Between April and June 2006, i.e. during the rainy season, further 226 women with live sin- gleton delivery were recruited. Both study protocols were reviewed and approved by the Ethics Committee, University of Science and Technology, Kumasi, and all women provided informed written consent. Sample collection as well as clinical and parasitological examinations were performed in an identical manner in 2000 and 2006 and have previously been described [23]. In brief, women were clinically examined and socio-demographic data documented. Information on chemoprophylaxis or IPTpSP was collected from antenatal care cards and verified by interviewing the women. Venous peripheral and placental blood samples were collected into EDTA. Malaria parasites were counted microscopically on Giemsa-stained thick blood films per 500 white blood cells (WBCs) for peripheral samples and per 100 high-power fields $(1,000 x)$ for placental samples. In the latter, the presence of leukocyte-associated haemozoin was also recorded. Slides were declared negative after having examined microscopic fields corresponding to 500 WBCs, or 100 high-power fields. Based on placental thick blood film microscopy, the stage of placental infection was categorized [27] as early, only parasites visible; late, both parasites and pigment present; resolved, only pigment visible; and none, neither parasites nor haemozoin present. In placental samples, $P$. falciparum was additionally diagnosed by detection of histidine-rich-protein 2 (HRP2) and nested PCR assays [28]. In 2000, HRP-2 was measured using the ICT Malaria P.f/P.v (Becton Dickinson, Germany) and, in 2006, using Malaria NOW P.f./P.v. (Inverness Medical, Germany). Haemoglobin (Hb) was measured by a HemoCue photometer (Ångelholm, Sweden) and anaemia and severe anaemia defined as $\mathrm{Hb}<11$ and $<7 \mathrm{~g} / \mathrm{dL}$, respectively. Fever was defined as an axillary temperature $\geq 37.5^{\circ} \mathrm{C}$ and LBW as a birth weight $<2500 \mathrm{~g}$.

For subsequent comparisons, three groups were formed, i) 226 women recruited in 2006, ii) 839 women recruited in 2000, and iii) 197 women who delivered in 2000 during a period exactly matching the recruitment phase in 2006 (29.04.-27.06.). Geometric mean parasite densities (GMPDs) and 95\% confidence intervals (95\%CIs) were calculated. Continuous variables were compared between groups by the non-parametric Mann-Whitney $U$ and Kruskal-Wallis tests as applicable, and proportions by $\chi^{2}$ test, Fisher's exact test and logistic regression models.

\section{Results}

The baseline characteristics of the three groups of delivering women are shown in Tables 1 and 2. In 2000, virtually all women stated to have used pyrimethamine $(25 \mathrm{mg}$ weekly) for chemoprophylaxis during pregnancy. In $2006,76.5 \%(173 / 226)$ of women reported to have taken IPTp-SP at least once, one women had used chloroquine chemoprophylaxis, and 23.0\% (52/226) neither IPTp nor chemoprophylaxis. Eight percent of the women $(17 / 208)$ 
Table I: Characteristics of women with live singleton delivery at Agogo Hospital, southern Ghana, in 2000 and 2006

\begin{tabular}{|c|c|c|c|c|c|}
\hline \multirow[b]{2}{*}{ Parameter } & \multicolumn{3}{|l|}{ Year of delivery } & \multirow[b]{2}{*}{2006 vs. $2000, P$} & \multirow[b]{2}{*}{$\begin{array}{l}2006 \text { vs. } 2000 \\
\text { subset, } P\end{array}$} \\
\hline & 2000 & $\begin{array}{l}\text { 2000, matching } \\
\text { dates subset }\end{array}$ & 2006 & & \\
\hline No. & 839 & 197 & 226 & - & - \\
\hline Residence in Agogo (\%) & 48.9 & 50.3 & 42.5 & 0.09 & 0.13 \\
\hline Age (years; median, range) & $25(15-47)^{\mathrm{a}}$ & $25(16-42)^{b}$ & $26(16-42)$ & 0.12 & 0.31 \\
\hline Proportion without school degree (\%) & I5.4 (I28/829) & $13.8(27 / 195)$ & $10.4(23 / 222)$ & 0.06 & 0.27 \\
\hline Parity (median, range) & $2(1-11)$ & $2(1-9)$ & $2(I-I I)$ & 0.14 & 0.43 \\
\hline Primiparae (\%) & $36.5(304 / 832)$ & $34.2(66 / 193)$ & 32.7 & 0.29 & 0.75 \\
\hline Proportion caesarean section (\%) & 22.1 & 18.3 & 24.8 & 0.38 & 0.11 \\
\hline No. of ANC visits (mean, range) & $3.9(0-12)$ & $3.9(0-11)$ & $4.5(0-14)$ & 0.01 & 0.047 \\
\hline Proportion with > 3 ANC visits & $52.3(429 / 82 I)$ & $48.7(93 / 191)$ & $58.7(131 / 223)$ & 0.08 & 0.04 \\
\hline Birth weight (g; median, range) & $2,950(1,280-4,500)^{c}$ & $2,900(1,450-4,350)$ & $3,080(1,600-5,460)^{d}$ & 0.02 & 0.0008 \\
\hline LBW (\%) & $16.0(134 / 838)$ & 19.3 & $12.4(28 / 225)$ & 0.19 & 0.05 \\
\hline Haemoglobin (g/dL; median, range) & $11.5(4.6-16.8)$ & $11.7(4.6-15.0)$ & $12.0(7.2-15.9)$ & $<0.0001$ & 0.04 \\
\hline Maternal anaemia (\%) & 35.2 & 33.0 & 23.5 & 0.0009 & 0.03 \\
\hline Severe anaemia $(\mathrm{Hb}<7 ; \%)$ & 1.8 & 1.5 & 0 & 0.05 & 0.10 \\
\hline Fever $(\%)$ & $2.8(23 / 826)$ & $1.5(3 / 196)$ & 6.6 & 0.006 & 0.01 \\
\hline
\end{tabular}

ANC, antenatal care; LBW, low birth weight; a $n=827$; b, $n=192 ;$ c, $n,=838$; d, $n=225$

in 2006 reported to have slept under a bed net the night before delivery.

As compared to 2000, women in 2006 more frequently had attended antenatal care, tended to be older, less likely to originate from Agogo, and more commonly to have a school degree. Maternal anaemia was reduced by $33 \%$ in 2006, severe anaemia absent, and median $\mathrm{Hb}(+0.5 \mathrm{~g} / \mathrm{dL})$ and median birth weight $(+130 \mathrm{~g})$ were higher. Fever occurred more often in 2006 than in 2000 (Table 1). The prevalence of microscopically confirmed placental parasi- taemia was more than halved (reduction by 57\%) in 2006 as compared to 2000, and parasite density reduced at boderline statistical significance. Similar reductions in the prevalence of infection were observed considering the results of pigment detection (by 43\%), HRP2 tests, and PCR (both by $46 \%$ ). The stage of placental infection, peripheral blood film positivity and peripheral parasite densisty were not significantly changed, however (Table 2). Comparing these parameters between women delivering in 2006 and women delivering during the matching

Table 2: Parasitological indices of delivering women at Agogo Hospital, southern Ghana, in 2000 and 2006

\begin{tabular}{|c|c|c|c|c|c|}
\hline \multirow[b]{2}{*}{ Parameter } & \multicolumn{3}{|c|}{ Year of delivery } & \multirow[b]{2}{*}{2006 vs. $2000, P$} & \multirow[b]{2}{*}{$\begin{array}{l}2006 \text { vs. } 2000 \\
\text { subset, } P\end{array}$} \\
\hline & 2000 & $\begin{array}{l}2000, \text { matching } \\
\text { dates subset }\end{array}$ & 2006 & & \\
\hline No. & 839 & 197 & 226 & & \\
\hline \multicolumn{6}{|l|}{ Placental infection (\%) } \\
\hline Microscopy & 34.9 & 29.9 & 15.0 & $<0.0001$ & 0.0002 \\
\hline Pigment & 30.9 & 31.0 & 17.7 & $<0.0001$ & 0.001 \\
\hline HRP2 & 40.8 & 38.6 & 22.1 & $<0.0001$ & 0.0002 \\
\hline PCR & 59.4 & 51.3 & 31.9 & $<0.0001$ & $<0.0001$ \\
\hline \multicolumn{6}{|l|}{ Stage of placental infection } \\
\hline Resolved & $17.9(64 / 357)$ & $28.1(23 / 82)$ & $27.7(13 / 47)$ & & \\
\hline Late & $54.6(195 / 357)$ & $46.3(38 / 82)$ & $57.4(27 / 47)$ & & \\
\hline Early & $27.5(98 / 357)$ & $25.6(21 / 82)$ & $14.9(7 / 47)$ & 0.10 & 0.31 \\
\hline Placental parasite density (GMPD, 95\%Cl) & $0.78(0.57-1.03)$ & $0.6 I(0.32-1.15)$ & $0.31(0.12-0.80)$ & 0.06 & 0.23 \\
\hline Peripheral blood film positive (\%) & 19.0 & 11.2 & 14.6 & 0.13 & 0.29 \\
\hline Peripheral parasite density (GMPD, $95 \% \mathrm{Cl}$ ) & $558(404-772)$ & $506(224-1142)$ & $891(366-2172)$ & 0.24 & 0.39 \\
\hline
\end{tabular}

HRP2, histidine rich protein 2, GMPD, geometric mean parasite density; $95 \% \mathrm{Cl}, 95 \%$ confidence interval 
period in 2000, basically the same results were seen (Tables 1 and 2).

Stratifying by parity, improvements in haematological and parasitological parameters in 2006 as compared to 2000 were found to be more pronounced in multiparae than in primiparae (Table 3 ). In contrast, there was a considerable reduction in the rate of LBW among primiparae but hardly a change in multiparae. Adjusting the 2000 data set for the months of recruitment in 2006 diminished these parity-dependent differences, particularly with respect to placental infection (Table 3), whereas regard of potential confounders (age, residence, antenatal care, educational status) did not have such an effect.

Next, women delivering in 2000 were compared with the small group of women delivering in 2006 who had not taken IPTp. Placental P. falciparum infection was non-significantly reduced by $12 \%$ to $17 \%$ in 2006 with the exemption of microscopically proven parasitaemia which dropped by $40 \%(P=0.03$; Tables 2 and 4$)$. Birth weight and $\mathrm{Hb}$ as well as the proportions of LBW and anaemia were very similar in these two groups (Tables 1 and 4 ).

Lastly, clincial and parasitological parameters of women delivering in 2006 were analysed according to the previous administration of IPTp (Table 4). All women previously on IPTp had attended antenatal care at least once, but also $80 \%(41 / 51)$ of those who had not taken IPTp ( $P$ $<0.0001$ ). Overall, $23.5 \%, 26.5 \%, 26.1 \%$, and $23.9 \%$ of the women had received none, one, two, and three doses of IPTp, respectively. The number of IPTp doses and antenatal care attendance were associated (Table 4 ). The proportion of women having used IPTp was similar in individuals from Agogo (79.2\%) and elsewhere (74.6\%; $P$ $=0.42$ ) as were the number of doses taken (both groups, median 2 , range $1-3 ; P=0.54)$. Primiparae $(70.3 \%)$ and multiparae $(79.6 \%)$ did not differ significantly in the use of IPTp $(P=0.12)$, or in the number of doses taken (both groups, median 2 , range $1-3 ; P=0.42$ ). The median gestational age (range) at IPTp doses one, two, and three was 24 (16-39), 28 (18-38), and 32 (22-37) weeks, respectively. The gestational week at the first IPTp administration was highest among women who had received one dose only $(28.5,19-39)$, and lower in women who had taken two $(24,16-32)$ or three doses $(20,16-24 ; P<$ 0.0001).

Overall, women who had received IPTp exhibited significantly less placental malaria and maternal anaemia than women who had not used IPTp; also, the former were older and had higher Hb concentrations (Table 4). Parasite densities did not differ between women with and without previous IPTp (data not shown). In women with three preceding doses of IPTp, birth weight and Hb concentrations were highest and anaemia least common. However, there was no clear-cut trend for less morbidity or placental malaria with increasing number of IPTp doses administered (Table 4).

\section{Discussion}

In this observational study, women delivering at a district hospital in rural southern Ghana after the implementation of IPTp-SP had significantly less placental malaria and anaemia and babies of higher birth weight than six years before when pyrimethamine chemoprophylaxis was the common mode of malaria prevention. This is a substantial improvement which, however, cannot exclusively be attributed to the implementation of IPTp since further factors known to be or potentially involved, e.g. antenatal care attendance, residence, and educational status, also changed over time. A further limitation of the present study is that malaria incidence or transmission intensity in Agogo and surroundings could have declined between

Table 3: Clinical and parasitological indices in delivering women according to parity and year of delivery

\begin{tabular}{|c|c|c|c|c|c|c|c|c|}
\hline \multirow[t]{2}{*}{ Parameter } & \multicolumn{4}{|l|}{ Primiparae } & \multicolumn{4}{|l|}{ Multiparae } \\
\hline & 2000 & 2006 & aOR $(95 \% \mathrm{Cl})$ & $P^{\dagger}$ & 2000 & 2006 & $\mathrm{aOR}(95 \% \mathrm{Cl})$ & $P^{\dagger}$ \\
\hline No. & 304 & 74 & & & 528 & 152 & & \\
\hline $\mathrm{Hb}$ (g/dL; median, range) & II.4 (4.6-I6.4) & II.6 (7.7-|4.8) & - & 0.11 & $11.6(4.7-16.8)$ & $12.1 *(7.2-15.9)$ & - & 0.08 \\
\hline Maternal anaemia (\%) & 38.5 & 35.1 & $0.74(0.37-1.46)$ & 0.38 & 33.5 & $17.8^{*}$ & $0.55(0.3 \mathrm{I}-0.96)$ & 0.04 \\
\hline $\begin{array}{l}\text { Birth weight } \\
\text { (g; median, range) }\end{array}$ & $2,785(1,280-4,000)$ & $2,900 *(1,600-4,600)$ & - & 0.006 & $3,020(1,500-4,500)$ & $3,130(1,650-5,460)$ & - & 0.02 \\
\hline LBW (\%) & 26.0 & 16.2 & $0.41(0.19-0.93)$ & 0.03 & $10.2(54 / 527)$ & $10.6(16 / 151)$ & $0.82(0.39-1.72)$ & 0.60 \\
\hline \multicolumn{9}{|l|}{ Placental infection (\%) } \\
\hline Microscopy & 46.1 & $25.7^{*}$ & $0.44(0.22-0.90)$ & 0.02 & 28.4 & $9.9 *$ & $0.39(0.20-0.76)$ & 0.006 \\
\hline Pigment & 42.4 & $27.0 *$ & $0.44(0.22-0.90)$ & 0.02 & 24.2 & $13.2^{*}$ & $0.49(0.26-0.91)$ & 0.02 \\
\hline HRP2 & 50.7 & 39.2 & $0.57(0.29-1.12)$ & 0.10 & 35.2 & $13.8^{*}$ & $0.35(0.19-0.63)$ & 0.0005 \\
\hline PCR & 65.1 & $44.6^{*}$ & $0.46(0.23-0.91)$ & 0.03 & 56.4 & $25.7^{*}$ & $0.4 I(0.25-0.68)$ & 0.0005 \\
\hline
\end{tabular}

aOR, odds ratio adjusted for months of recruitment in $2006 ; 95 \% \mathrm{Cl}, 95 \%$ confidence interval; *, bivariate comparison 2000 vs. $2006 ; P<0.05 \dagger, P$ value derived from logistic regression models, or from multiple linear regression models (coding: 0, 2000; I; 2006; and 0, non-matching recruitment period; $\mathrm{I}$, matching recruitment period) 
Table 4: Clinical and parasitological indices in delivering women in 2006 according to intermittent preventive treatment in pregnancy

\begin{tabular}{|c|c|c|c|c|c|}
\hline \multirow[t]{2}{*}{ Parameter } & \multicolumn{5}{|c|}{ Intermittent preventive treatment in pregnancy } \\
\hline & None $^{\mathrm{a}}$ & All & One dose & Two doses & Three doses \\
\hline No. & 53 & 173 & 60 & 59 & 54 \\
\hline Age & $24(17-42)$ & $27(|6-4|)^{*}$ & $26(16-40)$ & $26(16-40)$ & $28(|6-4|)^{*}$ \\
\hline Primiparae (\%) & 41.5 & 30.1 & 35.0 & 27.1 & 27.8 \\
\hline Proportion with > 3 ANC visits (\%) & $35.3(|8 / 5|)$ & $65.7 *(113 / 172)$ & 41.7 & $65.5 *(38 / 58)$ & $92.6 *$ \\
\hline Birth weight (g; median, range) & $2,900(1,820-4,000)$ & $3,100(1,600-5,460)$ & $3,025(2,200-5,460)$ & $3,100(1,600-4,250)$ & $3,125(2,030-4,100)$ \\
\hline LBW (\%) & I $5.4(8 / 52)$ & 11.6 & 10.0 & 15.3 & 9.3 \\
\hline $\mathrm{Hb}$ (g/dL; median, range) & $11.5(7.2-14.5)$ & $12.1(7.7-15.9)^{*}$ & I2.I (8.4-15.6)* & $11.9(7.7-14.4)$ & $12.4(9.3-15.9)^{*}$ \\
\hline Maternal anaemia (\%) & 39.6 & $18.5^{*}$ & $16.7^{*}$ & 27.1 & $11.1 *$ \\
\hline Fever (\%) & 1.9 & 8.1 & $13.3^{*}$ & 5.1 & 5.6 \\
\hline \multicolumn{6}{|l|}{ Placental infection (\%) } \\
\hline Microscopy & 20.8 & 13.3 & 13.3 & 15.3 & II.I \\
\hline Pigment & 26.4 & 15.0 & 15.0 & 15.3 & 14.8 \\
\hline HRP2 & 35.8 & $17.9 *$ & $13.3^{*}$ & 22.0 & $18.5^{*}$ \\
\hline PCR & 49.1 & $26.6^{*}$ & $21.7^{*}$ & 32.2 & $25.9 *$ \\
\hline
\end{tabular}

a, includes one women with previous chloroquine chemoprophylaxis; ${ }^{b}$, median, range; *, as compared to women without IPTp, $P<0.05$

2000 and 2006. The implementation of e.g. artemisininbased combination treatment in Ghana and other interventions might have led to a reduced malaria transmission and burden of disease. However, no dependable data are available to substantiate this. Though, in women in 2006 who did not take IPTp, the prevalence of placental infection (but not of LBW or anaemia) was lower than in 2000. However, this reduction did not have the magnitude seen in the 2006 group overall or among women having used IPTp. Moreover, comparing women delivering in 2006 with and without previous IPTp points into the same direction suggesting that IPTp in fact has markedly reduced the burden of malaria in pregnancy and related consequences. Still, 32\% of women delivering after the implementation of IPTp were found to be P. falciparum infected, and maternal anaemia and LBW occurred in $24 \%$ and $12 \%$, respectively, with higher figures among primiparae. This likely results from both, incomplete IPTp coverage and a remnant burden of disease which cannot further lowered even by complete coverage with this one measure of malaria control.

Data on IPTp-SP in West Africa are rare. In Mali and as compared to chloroquine chemoprophylaxis, 2-dose IPTp-SP significantly reduced the risks of placental parasitaemia, maternal anaemia, and LBW [11]. In a smaller trial from Nigeria, IPTp-SP was superior to pyrimethamine chemoprophyaxis in the prevention of parasitaemia and anaemia which was confirmed and complemented by a beneficial effect on birth weight in a recent observational study [29,30]. In Burkina Faso, the implementation of IPTp-SP in one district reduced placental parasitaemia and LBW, the latter, however, only when three doses had been taken [31]. Lastly, in The Gambia, IPTp-SP benefited multigravidae only when not protected by a bednet [32]. Altogether, these data show that IPTp-SP in West Africa is superior to available chemoprophylactic approaches but the effects achieved vary geographically and with the characteristics of the target population.

In the present study, only a quarter of delivering women had received all three recommended doses of IPTp-SP, and only half had taken two or more doses. Antenatal care attendance and both, use of IPTp-SP and number of doses were associated illustrating that efforts to promote antenatal care will likely be paralleled by increasing IPTp coverage, and, consequently, lead to even more pronounced effects than observed here. At Agogo hospital, the first dose of IPTp-SP was taken at a median gestational age of 24 weeks, i.e. roughly at halftime of pregnancy. While observed treatment during antental care visits is a major asset of IPTp, its comparatively late utilisation during pregnancy in general is a major drawback. Malaria early in pregnancy not only contributes to abortion but also to intrauterine growth retardation and LBW [2]. So far, it is unknown whether the pathophysiological changes and foetal damage induced by infections in early pregnancy are reversible and, thus, the extent of morbidity due to the relatively late initiation of IPTp cannot be estimated. Education and information campaigns flanking IPTp as well as community-based delivery systems may promote early initiation of IPTp and also improve access, attendance and adherence to the programme $[33,34]$. Further measures of malarial control, however, are needed to cover the vulnerable period of early pregnancy. Insecticide treated nets 
(ITNs) are a suitable and effective option [35], but the bed net coverage rate $(8 \%)$ seen in this study is far too low.

Primiparae in 2006 showed an only slightly lower rate of IPTp usage than multiparae arguing for a similar level of information and acceptance among women of different parities. Elsewhere, however, primiparity, young age, and, thereby, a presumed low level of malaria-related knowledge, might be an obstacle in taking up interventions such as IPTp. IPTp should be most effective in primiparae in whom antimalarial immunity is lowest and infection rates are highest $[1,4,6,7,23]$. In fact, data from East Africa and from multigravidae in The Gambia point into this direction $[8,32]$. Adjusting for the recruitment period, the reductions in placental malaria observed between 2000 and 2006 were similar in primi- and multiparae but the the reduction in maternal anaemia was significant only in the latter. The proportion of LBW, in contrast, declined significantly only in primiparae. Further adjustment for potential confounders did not fundamentally change these findings. These parity-dependent differences could reflect a differential effect of reducing the prevalence of malaria: in multiparae, increasing $\mathrm{Hb}$ concentrations might be the most visible sign of improved malaria prevention whereas the contribution of malaria to LBW is comparatively small [36]. In fact, the rate of LBW among multiparae in this study closely resembles the figure among African Americans [37]. In contrast, in primiparae the proportion of malaria-attributable LBW is larger than in multiparae [36], and IPTp-SP thus can achieve a greater extent of LBW reduction. So far, it is unclear why primiparae did not benefit from IPTp in haematological terms. Beyond a comparatively small sample size, this could stem from the still high prevalence of placental malaria in this group, or alternatively, reflect the importance of other, non-malaria causes of anemia. Such could involve e.g. iron deficiency which has previously been observed in only $5-18 \%$ of pregnant women in Agogo [22] and HIV infection, which occurs among $3 \%$ of pregnant women in Ghana [38].

No straightforward trend for less malaria, anaemia or LBW with increasing number of IPTp doses was observed in this study. Stratification into relatively small subgroups might be one reason. The sample size also impeded a meaningful analysis of the effects by parity and of the time when the last IPTp dose was given. The latter has been shown to unevenly influence the risk reduction of placental malaria in Kenya [39]. Selection of drug-resistant parasites during the course of IPTp-SP could also be involved but, so far, it is not understood whether and to which extent this occurs. In children, a substantial increase in the proportion of resistant parasites has been observed within weeks after preventive SP treatment [40].
Drug resistance might also be responsible for the prevalence of $26 \%$ of placental $P$. falciparum infection observed in women who had taken all three doses of IPTp-SP. Already in $2000,52 \%$ of placental $P$. falciparum isolates from Agogo hospital exhibited the triple dihydrofolate reductase mutation (Ile51+Arg59+Asn108) [41] which in Ghanaian children increases the risk of SP treatment failure ten-fold [42]. Preliminary data from a subset of the study participants indicate that this figure has increased to more than $75 \%$ in 2006 . While these findings support the utilisation of preventive approaches in addition to IPTpSP they also question the useful lifespan of IPTp-SP in the study area and support the urgent evaluation of alternative drugs.

\section{Conclusion}

In rural southern Ghana, the prevalences of placental malaria and of maternal anaemia have substantially been reduced following the implementation of IPTp-SP, and birth weight has increased. These achievements may be improved by increasing the proportion of pregnant women receiving IPTp-SP via enforced antenatal care services and information campaigns. Even then, however, a remnant prevalence of malaria in pregnancy will probably remain necessitating the implementation of further means of preventing malaria in pregnancy. Meanwhile, alternative options to SP in IPTp should urgently be evaluated.

\section{Authors' contributions}

FPM, GBA, TAE and UB designed the study. $\mathrm{LH}, \mathrm{CvO}, \mathrm{VH}$, PAA, and FPM were responsible for patient recruitment, and clinical and parasitological examinations. LH and FPM did the statistical analyses. LH, TAE and FPM wrote the paper with major contributions of the other authors.

\section{Acknowledgements}

We thank the mothers who participated in this study and the midwifes at Agogo Hospital. This study was supported by Charité (grants 99-640, 20005I2, 200I-6I3), MerkSharpDome, Germany (grant "Infectious Diseases 1999"), and Becton Dickinson (donation of ICT Malaria P.f/P.v tests) and forms part of the doctoral theses of $\mathrm{LH}$.

\section{References}

I. Brabin BJ: An analysis of malaria in pregnancy in Africa. Bull World Health Organ 1983, 61:1005-1016.

2. Sullivan AD, Nyirenda T, Cullinan T, Taylor T, Harlow SD, James SA, Meshnick SR: Malaria infection during pregnancy: intrauterine growth retardation and preterm delivery in Malawi. J Infect Dis 1999, I79: I580-1583.

3. Menendez C, Ordi J, Ismail MR, Ventura PJ, Aponte J], Kahigwa E, Font $\mathrm{F}$, Alonso PL: The impact of placental malaria on gestational age and birth weight. J Infect Dis 2000, I 8 I: | 740- I 745.

4. Steketee RW, Nahlen BL, Parise ME, Menendez C: The burden of malaria in pregnancy in malaria-endemic areas. Am J Trop Med Hyg 200I, 64( I-2 Suppl):28-35.

5. van Geertruyden JP, Thomas F, Erhart A, D'Alessandro U: The contribution of malaria in pregnancy to perinatal mortality. Am J Trop Med Hyg 2004, 7 I (2 Suppl):35-40.

6. Fried M, Nosten F, Brockman A, Brabin BJ, Duffy PE: Maternal antibodies block malaria. Nature 1998, 395:85I-852. 
7. O'Neil-Dunne I, Achur RN, Agbor-Enoh ST, Valiyaveettil M, Naik RS, Ockenhouse CF, Zhou A, Megnekou R, Leke R, Taylor DW, Gowda DC: Gravidity-dependent production of antibodies that inhibit binding of Plasmodium falciparum -infected erythrocytes to placental chondroitin sulfate proteoglycan during pregnancy. Infect Immun 200I, 69:7487-7492.

8. Verhoeff FH, Brabin BJ, Chimsuku L, Kazembe P, Russell WB, Broadhead RL: An evaluation of the effects of intermittent sulfadoxine-pyrimethamine treatment in pregnancy on parasite clearance and risk of low birthweight in rural Malawi. Ann Trop Med Parasitol 1998, 92: |4 I-I50.

9. Parise ME, Ayisi JG, Nahlen BL, Schultz LJ, Roberts JM, Misore A, Muga R, Oloo AJ, Steketee RW: Efficacy of sulfadoxinepyrimethamine for prevention of placental malaria in an area of Kenya with a high prevalence of malaria and human immunodeficiency virus infection. Am J Trop Med Hyg 1998, 59:8| 3-822.

10. van Eijk AM, Ayisi JG, ter Kuile FO, Otieno JA, Misore AO, Odondi JO, Rosen DH, Kager PA, Steketee RW, Nahlen BL: Effectiveness of intermittent preventive treatment with sulphadoxinepyrimethamine for control of malaria in pregnancy in western Kenya: a hospital-based study. Trop Med Int Health 2004, 9:351-360.

II. Kayentao K, Kodio M, Newman RD, Maiga H, Doumtabe D, Ongoiba A, Coulibaly D, Keita AS, Maiga B, Mungai M, Parise ME, Doumbo O: Comparison of intermittent preventive treatment with chemoprophylaxis for the prevention of malaria during pregnancy in Mali. J Infect Dis 2005, 191:109-1 I6.

12. Garner P, Gülmezoglu AM: Drugs for preventing malaria in pregnant women. Cochrane Database of Systematic Reviews 2006 4:CD000169.

13. Peters PJ, Thigpen MC, Parise ME, Newman RD: Safety and toxicity of sulfadoxine/pyrimethamine : Implications for malaria prevention in pregnancy using intermittent preventive treatment. Drug Safety 2007, 30:48I-50I.

14. WHO: A strategic framework for malaria prevention and control during pregnancy in the African region. Brazzaville, Congo: World Health Organization; 2004.

15. Crawley J, Hill J, Yartey J, Robalo M, Serufilira A, Ba-Nguz A, Roman E, Palmer A, Asamoa K, Steketee R: From evidence to action? Challenges to policy change and programme delivery for malaria in pregnancy. Lancet Infect Dis 2007, 7:| $45-155$.

16. Hill J, Kazembe P: Reaching the Abuja target for intermittent preventive treatment of malaria in pregnancy in African women: a review of progress and operational challenges. Trop Med Int Health 2006, I I:409-4I8.

17. Wongsrichanalai C, Pickard AL, Wernsdorfer WH, Meshnick SR: Epidemiology of drug-resistant malaria. Lancet Infect Dis 2002 2:209-218

18. White NJ: Sulfadoxine-pyrimethamine for uncomplicated falciparum malaria: sulfadoxine-pyrimethamine is not working in Malawi. BMJ 2004, 328: I 259.

19. ter Kuile FO, van Eijk AM, Filler SJ: Effect of sulfadoxinepyrimethamine resistance on the efficacy of intermittent preventive therapy for malaria control during pregnancy: a systematic review. JAMA 2007, 297:2603-26I6.

20. Newman RD, Moran AC, Kayentao K, Benga-De E, Yameogo M, Gaye O, Faye O, Lo Y, Moreira PM, Doumbo O, Parise ME, Steketee RW Prevention of malaria during pregnancy in West Africa: policy change and the power of subregional action. Trop Med Int Health 2006, I I:462-469.

21. Mockenhaupt FP, Rong B, Till H, Eggelte TA, Beck S, Gyasi-Sarpong C, Thompson WN, Bienzle U: Submicroscopic Plasmodium falciparum infections in pregnancy in Ghana. Trop Med Int Health 2000, 5:167-173.

22. Mockenhaupt FP, Rong B, Günther M, Beck S, Till H, Kohne E, Thompson WN, Bienzle U: Anaemia in pregnant Ghanaian women: importance of malaria, iron deficiency, and haemoglobinopathies. Trans R Soc Trop Med Hyg 2000, 94:477-83.

23. Mockenhaupt FP, Bedu-Addo G, von Gaertner C, Boyé R, Fricke K Hannibal I, Karakaya F, Schaller M, Ulmen U, Acquah PA, Dietz E, Eggelte TA, Bienzle U: Detection and clinical manifestation of placental malaria in southern Ghana. Malar J 2006, 5:119.

24. Mockenhaupt FP, Ehrhardt S, Dzisi SY, Teun Bousema J, Wassilew N, Schreiber J, Anemana SD, Cramer JP, Otchwemah RN, Sauerwein RW, Eggelte TA, Bienzle U: A randomized, placebo-controlled, double-blind trial on sulfadoxine-pyrimethamine alone or combined with artesunate or amodiaquine in uncomplicated malaria. Trop Med Int Health 2005, 10:512-520.

25. Tagbor $\mathrm{H}$, Bruce J, Browne E, Randal A, Greenwood B, Chandramohan D: Efficacy, safety, and tolerability of amodiaquine plus sulphadoxine-pyrimethamine used alone or in combination for malaria treatment in pregnancy: a randomised trial. Lancet 2006, 368: 1349-1356.

26. Browne EN, Frimpong E, Sievertsen J, Hagen J, Hamelmann C, Dietz K, Horstmann RD, Burchard GD: Malariometric update for the rainforest and savanna of Ashanti region, Ghana. Ann Trop Med Parasitol 2000, 94:15-22.

27. Fried M, Muga RO, Misore AO, Duffy PE: Malaria elicits type I cytokines in the human placenta: IFN-gamma and TNFalpha associated with pregnancy outcomes. J Immunol 1998 , 160:2523-2530.

28. Snounou G, Viriyakosol S, Zhu XP, Jarra W, Pinheiro L, do Rosario $\mathrm{VE}$, Thaithong S, Brown KN: High sensitivity of detection of human malaria parasites by the use of nested polymerase chain reaction. Mol Biochem Parasitol 1993, 6 I:315-320.

29. Tukur IU, Thacher TD, Sagay AS, Madaki JK: A comparison of sulfadoxine-pyrimethamine with chloroquine and pyrimethamine for prevention of malaria in pregnant Nigerian women. Am J Trop Med Hyg 2007, 76:1019-1023.

30. Falade CO, Yusuf BO, Fadero FF, Mokuolu OA, Hamer DH, Salako LA: Intermittent preventive treatment with sulphadoxinepyrimethamine is effective in preventing maternal and placental malaria in Ibadan, south-western Nigeria. Malar J 2007, 6:88.

31. Sirima SB, Cotte AH, Konate A, Moran AC, Asamoa K, Bougouma EC, Diarra A, Ouedraogo A, Parise ME, Newman RD: Malaria prevention during pregnancy: assessing the disease burden one year after implementing a program of intermittent preventive treatment in Koupela District, Burkina Faso. Am J Trop Med Hyg 2006, 75:205-2II.

32. Mbaye A, Richardson K, Balajo B, Dunyo S, Shulman C, Milligan P, Greenwood B, Walraven G: A randomized, placebo-controlled trial of intermittent preventive treatment with sulphadoxine-pyrimethamine in Gambian multigravidae. Trop Med Int Health 2006, I I:992-1002.

33. Mbonye AK, Bygbjerg I, Magnussen P: Intermittent preventive treatment of malaria in pregnancy: a community-based delivery system and its effect on parasitemia, anemia and low birth weight in Uganda. Int J Infect Dis 2007. doi:10.1016/ j.jij. 2006. 10.008

34. Ouma PO, Van Eijk AM, Hamel MJ, Sikuku E, Odhiambo F, Munguti K, Ayisi JG, Kager PA, Slutsker L: The effect of health care worker training on the use of intermittent preventive treatment for malaria in pregnancy in rural western Kenya. Trop Med Int Health 2007, I 2:953-96I.

35. ter Kuile FO, Terlouw DJ, Phillips-Howard PA, Hawley WA, Friedman JF, Kariuki SK, Shi YP, Kolczak MS, Lal AA, Vulule JM, Nahlen BL: Reduction of malaria during pregnancy by permethrintreated bed nets in an area of intense perennial malaria transmission in western Kenya. Am J Trop Med Hyg 2003, 68(4 Suppl):50-60.

36. McGregor IA, Wilson ME, Billewicz WZ: Malaria infection of the placenta in The Gambia, West Africa; its incidence and relationship to stillbirth, birthweight and placental weight. Trans $R$ Soc Trop Med Hyg 1983, 77:232-244.

37. Howard DL, Marshall SS, Kaufman JS, Savitz DA: Variations in low birth weight and preterm delivery among blacks in relation to ancestry and nativity: New York City, 1998-2002. Pediatrics 2006, I I 8:el399-|405.

38. Ghana Aids Commission: HIV Sentinel Surveillance Report 2005. [http://www.ghanaids.gov.gh/gac/publications/index.php]

39. van Eijk AM, Ayisi JG, ter Kuile FO, Otieno JA, Misore AO, Odond JO, Rosen DH, Kager PA, Steketee RW, Nahlen BL: Effectiveness of intermittent preventive treatment with sulphadoxinepyrimethamine for control of malaria in pregnancy in western Kenya: a hospital-based study. Trop Med Int Health 2004, 9:351-360.

40. Marks F, von Kalckreuth V, Kobbe R, Adjei S, Adjei O, Horstmann $\mathrm{RD}$, Meyer CG, May J: Parasitological rebound effect and emergence of pyrimethamine resistance in Plasmodium falciparum 
after single-dose sulfadoxine-pyrimethamine. J Infect Dis 2005, 192:1962-1965.

41. Mockenhaupt FP, Bedu-Addo G, Junge C, Hommerich L, Eggelte TA, Bienzle U: Markers of sulfadoxine-pyrimethamine-resistant Plasmodium falciparum in placenta and circulation of pregnant women. Antimicrob Agents Chemother 2007, 5 I:332-334.

42. Mockenhaupt FP, Teun Bousema J, Eggelte TA, Schreiber J, Ehrhardt S, Wassilew N, Otchwemah RN, Sauerwein RW, Bienzle U: Plasmodium falciparum dhfr but not dhps mutations associated with sulphadoxine-pyrimethamine treatment failure and gametocyte carriage in northern Ghana. Trop Med Int Health 2005, 10:901-908.

Publish with Bio Med Central and every scientist can read your work free of charge

"BioMed Central will be the most significant development for disseminating the results of biomedical research in our lifetime. "

Sir Paul Nurse, Cancer Research UK

Your research papers will be:

- available free of charge to the entire biomedical community

- peer reviewed and published immediately upon acceptance

- cited in PubMed and archived on PubMed Central

- yours - you keep the copyright

Submit your manuscript here:

http://www.biomedcentral.com/info/publishing_adv.asp 